\title{
Dental Findings of Kidney and Liver Transplantation Patients from a Brazilian Oral Health Care Service
}

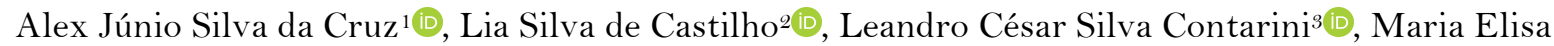

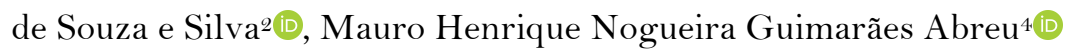

\begin{abstract}
${ }^{1}$ Graduate Programme in Dentistry, School of Dentistry, Federal University of Minas Gerais, Belo Horizonte, MG, Brazil.
${ }^{2}$ Department of Operative Dentistry, School of Dentistry, Federal University of Minas Gerais, Belo Horizonte, MG, Brazil.

${ }^{3}$ Undergraduate Programme in Dentistry, School of Dentistry, Federal University of Minas Gerais, Belo Horizonte, MG, Brazil.

${ }^{4}$ Department of Community and Preventive Dentistry, School of Dentistry, Federal University of Minas Gerais, Belo Horizonte, MG, Brazil.
\end{abstract}

Correspondence: Alex Júnio Silva da Cruz, Colegiado de Pós-Graduação em Odontologia, Faculdade de Odontologia, Universidade Federal de Minas Gerais, Av. Presidente Antônio Carlos, 6627, Pampulha, Belo Horizonte, MG, Brazil. 31270-901. E-mail: junio.alex@,hotmail.com

Academic Editor: Alessandro Leite Cavalcanti

Received: 20 August 2020 / Review: 22 September 2020 / Accepted: 12 October 2020

How to cite: Cruz AJS, Castilho LS, Contarini LCS, Silva MES, Abreu MHNG. Dental findings of kidney and liver transplantation patients from a Brazilian oral health care service. Pesqui Bras Odontopediatria Clín Integr. 202 1; $21: e 0187$. https://doi.org/10.1590/pboci.2021.042

\begin{abstract}
Objective: To describe dental findings of kidney and liver, pre and post-transplant patients of an oral health care service from a Brazilian Southeast state. Material and Methods: A descriptive cross-sectional study was developed with a sample of patients attending the oral health care program for transplantation of Universidade Federal de Minas Gerais. Participants were divided into two groups according to the kind of transplantation-kidney or liver. Characteristics of the sample, sex (male/female), age (18-44; 45-54; 55-80), living region (Belo Horizonte, or outside), phase of transplantation (pre-Tx or post-Tx), and self-report of diabetes mellitus and hypertension were presented by frequencies. Dental caries experienced was measured by Decayed, Missing and Filled-Teeth (DMF-T) index. Results: 185 patients, kidney (46; 24.9\%), and liver (139; 75.1\%) were included. Mean DMFT was 18.3 (20.0). DMFT scores of males (18.7; 20.0), females (17.2; 18.0), pre-transplanted $(18.3 ; 20.0)$, and post-transplanted $(18.1 ; 20.0)$ were similar. The liver transplantation group $(19.3 ; 20.0)$ showed higher caries experience comparing to kidney's (15.2; 17.0). Conclusion: Dental caries experience was high in kidney and liver patients under transplantation therapy. This highlights the demand for treatment need in this population.
\end{abstract}

Keywords: Dental Caries; Kidney Transplantation; Liver Transplantation; Dental Health Services. 


\section{Introduction}

In December 1954, the kidney was the first human successfully solid organ transplantation (SOT). A couple of years ahead, in the 1960s, other SOT, such as liver, heart, and pancreas was performed [1]. Since there, consistent improvements in the surgical approach and the immunosuppressive pharmacotherapy made transplantation the standard therapy for patients with irreversible liver failure and end-stage kidney disease (ESKD) [2,3]. Irreversible liver failure is caused by a range of conditions, for example, hepatitis C, alcoholic cirrhosis, and cancer [2]. ESKD indicates the demand for treatment by replacement therapy, either by dialysis or by transplantation. Uncontrolled hypertension and diabetes mellitus are the leading causes of ESKD [4,5].

In the patients ongoing pre-transplant (pre-Tx) and post-transplant (post-TX) therapy, some oral manifestations may be observed. Some studies reported alterations in the salivary composition, flow, buffering capacity, and the levels of immunoglobulins, IgA, for instance [6-8]. The colonization of the oral cavity by some microorganisms seems to be increased [7,9-11]. Besides, the new lifestyle challenges by the transplantation may lead to a reduced priority for dental care [12]. These factors can increase the risk of dental caries.

Dental caries is a multifactorial biofilm-modulated disease determined by biological, socioenvironmental, and behavioral factors that result in the destruction of the tooth hard tissues [13,14]. If not detected and managed in early stages, small caries lesions tend to increase the degree of tooth destruction reaching the pulp and inducing bacteremia in the periapical region [13,15]. Untreated oral conditions can represent a risk factor for infections [16,17]. Post-Tx patients are immunosuppressive to avoid grafting rejection, which makes them vulnerable to infectious diseases [18].

The omission of dental care before transplantation was associated with an elevated risk of infection [19]. A survey in the United States' transplant centers reported that post-transplantation sepsis from a possible dental origin was acknowledged in $27 \%$ of the centers. Furthermore, due to dental infection, $38 \%$ of respondents stated that transplantations were postponed or canceled [20]. A multinational cohort study reported that edentulousness, and Decayed, Missing and Filled Teeth (DMF-T) index greater than 14 were associated with early mortality in ESKD patients waiting for transplantation [21]. This highlights the relevance of dental practitioners in the multidisciplinary SOT team. The adoption of protocols for dental screening before and after transplantation is associated with reduced risk of infection in the oral cavity, decreased utilization of prescribed medicines, early dental rehabilitation, and increased oral health-related quality of life [17,22].

During the years 2018 and 2019, 14,477 kidney and liver transplantations have been performed in Brazil [23]. Previous studies worldwide have shown poor oral health status and high treatment need of patients under transplantation therapy [11,12,24-26]. Although the expressive number of SOT in Brazil, little is known about the oral health status of candidates for transplantation in our country. In this manner, this research aimed to describe dental findings of kidney and liver, pre-Tx and post-Tx, patients of an oral health care service from a Brazilian Southeast state.

\section{Material and Methods}

Study Design

This is a descriptive cross-sectional study carried out in the state of Minas Gerais (MG), located in the Brazilian Southeast. MG is the second most populous state in the country (19,597,330 inhabitants), including 853 municipalities [27]. According to the last epidemiological report published by MG Transplant - the 
institution responsible for coordinating the SOT and soft tissue transplantation policy in the state - 2,294 and 47 candidates were on the waiting list for kidney and liver grafting, respectively [28].

Sample and Data Collection

The sample of this study was composed of patients attending the oral health care program for transplantation of Universidade Federal de Minas Gerais, located in Belo Horizonte, capital of the state of MG. This program started in 2002 with blood narrow patients ongoing transplantation. About ten years later, the program initiated oral health care management in liver transplantation patients and, more recently, renal. The program's main goals include comprehensive, efficient, and quick oral treatment for patients on transplantation therapy. This kind/type of service, with the diversity of procedures available, maybe is unique in Brazil.

A secondary database produced with patients' dental records from March 2012 to March 2020 was analyzed in this study. The database includes patient's dental caries experience, socio-demographic and clinical characteristics. Dental caries was measured by the DMF-T index, according to the recommendations for oral health surveys from the World Health Organization [29]. Undergraduate students performed clinical exams, but all diagnoses were checked by a professor of the program. Other variables included sex (male/female), age (18-44; 45-54; 55-80), living region (Belo Horizonte, or outside), phase of transplantation (pre-Tx or post-Tx) and self-report of diabetes mellitus and hypertension. The following inclusion criteria were required for this research: kidney and liver pre-Tx or, post-Tx patients. Subjects under the age of 18 years and the cases without information on caries experience, socio-demographic and clinical characteristics were excluded.

\section{Data Analysis}

Descriptive statistics was performed using the Statistical Package for the Social Sciences (SPSS for Windows version 25.0, SPSS Inc., Chicago, USA). The characteristics of the sample are presented by frequency and proportion. Dental caries experience is presented as mean and median DMFT scores.

\section{Ethical Clearance}

The study was approved by ethics committee of Universidade Federal de Minas Gerais (Protocol number CAAE-77375517.9.0000.5149). The participants were verbally informed about the research and provided written informed consent for participation.

\section{Results}

A total of 185 patients, including $46(24.9 \%)$ kidney (pre-Tx=37 [80.4\%]; post-Tx=9 [19.6\%]), and $139(75.1 \%)$ liver (pre-Tx=109 [78.4\%]; post-Tx=30 [21.6\%]), were included in this study. $71.4 \%(\mathrm{n}=132)$ were male. Table 1 shows the characteristics of the sample.

Table 1. Characteristics of the sample.

\begin{tabular}{|c|c|c|c|}
\hline Variables & $\begin{array}{c}\text { Kidney Tx } \\
\text { N }(\%)\end{array}$ & $\begin{array}{c}\text { Liver Tx } \\
\text { N (\%) }\end{array}$ & $\begin{array}{c}\text { Kidney } \mathbf{T x}+\text { Liver } \mathbf{T x} \\
\mathrm{N}(\%)\end{array}$ \\
\hline \multicolumn{4}{|l|}{ Sex } \\
\hline Male & $27(58.7 \%)$ & $105(75.5 \%)$ & $132(71.4 \%)$ \\
\hline Female & $19(41.3 \%)$ & $34(24.5 \%)$ & $53(28.6 \%)$ \\
\hline \multicolumn{4}{|l|}{ Age (Years) } \\
\hline 18 to 44 & $20(43.5 \%)$ & $31(22.3 \%)$ & $51(27.6 \%)$ \\
\hline 45 to 54 & $10(21.7 \%)$ & $32(23.0 \%)$ & $42(22.7 \%)$ \\
\hline 55 to 80 & $16(34.8 \%)$ & $76(54.7 \%)$ & $92(49.7 \%)$ \\
\hline
\end{tabular}

Living Region 


\begin{tabular}{lccc} 
Belo Horizonte & $26(56.5 \%)$ & $73(52.5 \%)$ & $99(53.5 \%)$ \\
Outside Belo Horizonte & $20(43.5 \%)$ & $66(47.5 \%)$ & $86(46.5 \%)$ \\
$\begin{array}{l}\text { Phase of Transplantation } \\
\text { Pre-Tx }\end{array}$ & $37(80.4 \%)$ & $109(78.4 \%)$ & $146(78.9 \%)$ \\
Post- Tx & $9(19.6 \%)$ & $30(21.6 \%)$ & $39(21.1 \%)$ \\
$\begin{array}{l}\text { Diabetes Mellitus } \\
\text { No }\end{array}$ & $37(80.4 \%)$ & $103(74.1 \%)$ & $140(75.7 \%)$ \\
Yes & $9(19.6 \%)$ & $36(25.9 \%)$ & $45(24.3 \%)$ \\
Hypertension & $14(30.4 \%)$ & $90(64.7 \%)$ & $104(56.2 \%)$ \\
No & $32(69.6 \%)$ & $49(35.3 \%)$ & $81(43.8 \%)$ \\
Yes Total & $46(24.9)$ & $139(75.1)$ & $185(100.0)$ \\
\hline
\end{tabular}

Mean DMFT was 18.3 (Median = 20.0), decayed teeth $(1.6 ; 1.0)$, missing teeth $(9.1 ; 7.0)$, filled teeth (7.6; 6.0). Edentulous accounted for 3.8\% $(\mathrm{n}=7)$, while only $1(0.5 \%)$ participant was caries-free. Mean DMFT scores of males (18.7; 20.0), females (17.2; 18.0), pre-Tx (18.3; 20.0), and post-TX (18.1; 20.0) were similar. Dental caries experience increased with age, ranging from mean 12.7 (13.0) affected teeth in the age bracket of 18-44 years to 21.2 (23.0) affected teeth in the age bracket of 55-80 years. Higher caries experience was observed in the liver transplantation group (19.3; 20.0) compared to kidney's (15.2; 17.0). DMFT scores are presented for kidney and liver transplantation groups and the whole sample in Table 2 .

\section{Discussion}

This study described dental findings from 185 kidney and liver, pre-Tx and post-Tx, patients. The majority were male candidates for a liver. The prevalence of dental caries was high in both groups. However, the mean DMF-T was smaller in the kidney transplantation patients. Also, dental caries experience and severity increased with age.

Considering the entire sample, we found high values of DMF-T. In a previous study [12] developed with SOT (heart, liver, and kidney) patients, mean DMF-T pre-transplantation $(18.1 \pm 5.3)$ and posttransplantation $(16.8 \pm 8.3)$ showed similarity with our findings. Several studies reported poor habits of oral hygiene and poor oral health status among adults under transplantation therapy [11,25,30-32]. Factors, such as modifications in lifestyle, usage of medicines that reduce salivary flow, and the high burden of ESKD and chronic liver disease in pre-Tx candidates, seem to reduce dental care priorities in this population, increasing the development of caries lesions [32].

In the reviewed literature, we found two studies developed in the Brazilian Northeast that evaluated oral health status of kidney and liver pre-Tx patients. Menezes et al. [10] reported a mean DMF-T in patients under dialysis therapy in the state of Maranhão, Brazil, similar to our findings. However, D-component and Mcomponent were higher but, F-component was smaller than our findings. Considering liver pre-Tx, Lins et al. [32] reported a mean DMF-T in accordance with our results. Nonetheless, mean D-component was high compared to our data, and mean F-component, was small.

In comparison to the Southeast region, the Northeast presents higher levels of poverty [27]. It has been reported earlier [33,34] there is a relationship between inequalities and the burden of oral diseases and dental caries, access to, and utilization of oral health care services. This may partially explain the higher values of $\mathrm{D}$ and M-components but low values of F-component of DMF-T index in the Northeast. National epidemiological surveys showed similar trends within the general population [35]. In this matter, multicenter studies among patients under transplantation therapy in different regions of Brazil could provide evidence about the inequalities in the burden of oral diseases in this group. 
Table 2. Decayed, Missing, and Filled Teeth (DMF-T) index of kidney and liver patients under transplantation therapy.

\begin{tabular}{|c|c|c|c|c|c|c|c|c|c|c|c|c|}
\hline \multirow[b]{2}{*}{ Variables } & \multicolumn{4}{|c|}{ Kidney $\mathbf{T x}$} & \multicolumn{4}{|c|}{ Liver $\mathbf{T x}$} & \multicolumn{4}{|c|}{ Kidney Tx + Liver Tx } \\
\hline & $\begin{array}{c}\mathrm{DT} \\
(\mathrm{Me} / \mathrm{Md})\end{array}$ & $\begin{array}{c}\mathrm{MT} \\
(\mathrm{Me} / \mathrm{Md})\end{array}$ & $\begin{array}{c}\mathrm{FT} \\
(\mathrm{Me} / \mathrm{Md})\end{array}$ & $\begin{array}{c}\text { DMF-T } \\
(\mathrm{Me} / \mathrm{Md})\end{array}$ & $\begin{array}{c}\mathrm{DT} \\
(\mathrm{Me} / \mathrm{Md})\end{array}$ & $\begin{array}{c}\mathrm{MT} \\
(\mathrm{Me} / \mathrm{Md})\end{array}$ & $\begin{array}{c}\mathrm{FT} \\
(\mathrm{Me} / \mathrm{Md})\end{array}$ & $\begin{array}{c}\text { DMF-T } \\
(\mathrm{Me} / \mathrm{Md})\end{array}$ & $\begin{array}{c}\mathrm{DT} \\
(\mathrm{Me} / \mathrm{Md})\end{array}$ & $\begin{array}{c}\text { MT } \\
(\mathrm{Me} / \mathrm{Md})\end{array}$ & $\begin{array}{c}\text { FT } \\
(\mathrm{Me} / \mathrm{Md})\end{array}$ & $\begin{array}{c}\text { DMF-T } \\
(\mathrm{Me} / \mathrm{Md})\end{array}$ \\
\hline \multicolumn{13}{|l|}{ Sex } \\
\hline Male & $2.4(1.0)$ & $5.1(3.0)$ & $6.7(5.0)$ & $14.2(15.0)$ & $1.6(1.0)$ & $11.1(9.0)$ & $7.2(6.0)$ & $19.9(21.0)$ & $1.8(1.0)$ & $9.9(8.0)$ & $7.1(6.0)$ & $18.7(20.0)$ \\
\hline Female & $1.0(1.0)$ & $6.7(5.0)$ & $8.9(9.0)$ & $16.7(18.0)$ & $1.3(1.0)$ & $7.7(4.5)$ & $8.8(9.5)$ & $17.4(18.0)$ & $1.2(1.0)$ & $7.3(5.0)$ & $8.8(9.0)$ & $17.2(18.0)$ \\
\hline \multicolumn{13}{|l|}{ Age (Years) } \\
\hline 18 to 44 & $3.0(1.5)$ & $3.3(1.0)$ & $6.6(3.5)$ & $12.8(12.5)$ & $1.8(1.0)$ & $4.0(3.0)$ & $6.8(5.0)$ & $12.6(13.0)$ & $2.3(1.0)$ & $3.7(2.0)$ & $6.7(5.0)$ & $12.7(13.0)$ \\
\hline 45 to 54 & $1.0(1.0)$ & $4.4(3.5)$ & $10.0(10.5)$ & $15.6(17.0)$ & $1.9(2.0)$ & $9.6(8.5)$ & $7.9(6.5)$ & $19.4(19.0)$ & $1.7(1.0)$ & $8.4(7.5)$ & $8.4(8.0)$ & $18.5(19.0)$ \\
\hline 55 to 80 & $0.9(0.5)$ & $9.8(7.0)$ & $7.4(7.5)$ & $18.1(18.5)$ & $1.2(0.0)$ & $13.1(13.0)$ & $7.7(6.5)$ & $21.9(23.0)$ & $1.2(0.0)$ & $12.5(12.0)$ & $7.6(6.5)$ & $21.2(23.0)$ \\
\hline \multicolumn{13}{|l|}{ Living Region } \\
\hline Belo Horizonte & $1.7(1.0)$ & $4.5(3.0)$ & $7.9(7.0)$ & $14.1(17.0)$ & $1.5(1.0)$ & $9.8(8.0)$ & $8.1(8.0)$ & $19.2(20.0)$ & $1.5(1.0)$ & $8.4(5.0)$ & $8.0(8.0)$ & $17.9(19.0)$ \\
\hline Outside Belo Horizonte & $2.1(1.5)$ & $7.5(5.0)$ & $7.2(6.0)$ & $16.8(16.5)$ & $1.5(1.0)$ & $10.8(9.0)$ & $7.0(5.0)$ & $19.3(20.0)$ & $1.7(1.0)$ & $10.0(8.0)$ & $7.0(6.0)$ & $18.7(20.0)$ \\
\hline \multicolumn{13}{|l|}{ Phase of Transplantation } \\
\hline Pre-transplantation & $1.6(1.0)$ & $5.8(4.0)$ & $6.9(5.0)$ & $14.3(16.0)$ & $1.6(1.0)$ & $10.8(9.0)$ & $7.3(5.0)$ & $19.7(21.0)$ & $1.6(1.0)$ & $9.5(7.0)$ & $7.2(5.0)$ & $18.3(20.0)$ \\
\hline Post-transplantation & $2.7(1.0)$ & $5.9(3.0)$ & $10.6(9.0)$ & $19.0(18.0)$ & $1.3(0.5)$ & $8.2(6.5)$ & $8.3(8.0)$ & $17.8(20.0)$ & $1.6(1.0)$ & $7.7(6.0)$ & $8.8(9.0)$ & $18.1(20.0)$ \\
\hline \multicolumn{13}{|l|}{ Diabetes Mellitus } \\
\hline No & $2.0(1.0)$ & $5.9(3.0)$ & $8.1(9.0)$ & $16.0(18.0)$ & $1.6(1.0)$ & $9.8(8.0)$ & $7.7(6.0)$ & $19.0(20.0)$ & $1.7(1.0)$ & $8.8(6.0)$ & $7.8(7.0)$ & $18.2(19.5)$ \\
\hline Yes & $1.2(1.0)$ & $5.3(4.0)$ & $5.4(4.0)$ & $12.2(11.0)$ & $1.2(0.5)$ & $11.6(9.5)$ & $7.1(6.0)$ & $20.0(21.5)$ & $1.2(1.0)$ & $10.4(9.0)$ & $6.8(6.0)$ & $18.4(20.0)$ \\
\hline \multicolumn{13}{|l|}{ Hypertension } \\
\hline No & $2.9(1.0)$ & $3.0(1.0)$ & $7.8(7.5)$ & $13.6(14.0)$ & $1.5(1.0)$ & $9.7(8.0)$ & $7.9(6.5)$ & $18.9(20.0)$ & $1.7(1.0)$ & $8.8(7.0)$ & $7.9(6.5)$ & $18.2(19.5)$ \\
\hline Yes & $1.4(1.0)$ & $7.0(4.0)$ & $7.5(6.0)$ & $15.9(18.0)$ & $1.6(1.0)$ & $11.3(10.0)$ & $7.0(6.0)$ & $19.9(20.0)$ & $1.5(1.0)$ & $9.6(6.0)$ & $7.2(6.0)$ & $18.3(20.0)$ \\
\hline Total & $1.8(1.0)$ & $5.8(3.5)$ & $7.6(6.0)$ & $15.2(17.0)$ & $1.5(1.0)$ & $10.3(8.0)$ & $7.6(6.0)$ & $19.3(20.0)$ & $1.6(1.0)$ & $9.1(7.0)$ & $7.6(6.0)$ & $18.3(20.0)$ \\
\hline
\end{tabular}

$\mathrm{Me}=$ Mean; Md = Median; DT = Decayed Teeth; MT = Missing Teeth; FT= Filled Teeth; 
Published research regarding dental caries experience in patients under transplantation therapy is controversial. Similar, low, and high DMF-T indices among pre-Tx and post-Tx groups have been reported [7,10-12,25,31]. In the kidney group, our findings showed higher DMF-T scores in post-Tx. Differently, Schmalz et al. [11] described higher DMF-T in the kidney pre-Tx group (19.47 \pm 5.84$)$ compared to post-Tx $(17.61 \pm 5.81)$. Considering the liver group, we found small DMF-T scores in the post-Tx. Similar results were reported by one study conducted in Germany, which mean DMF-T of liver pre-Tx (23.7 \pm 4.0$)$ was higher than post-Tx $(22.8 \pm 5.2)[25]$. It is noteworthy that, in our research and both discussed studies [11,25], different patients under pre-Tx and post-Tx therapy were assessed. Therefore, this limits comparisons. Moreover, discrepancies in dental caries experience may be explained by different studied populations and methodologies, age groups and, characteristics of health care services in the countries.

This study has some limitations that should be addressed. The limited level of evidence produced by the cross-sectional design. Different kidney and liver, pre-Tx, and post-Tx patients were investigated in this study; therefore, the results must be interpreted with caution. We used a secondary database, which data was not collected specifically for this research. Associated factors to dental caries in transplanted patients, such as the use of medicines that decrease salivary flow and immunosuppressors, could not be assessed. Furthermore, the time in the waiting list and after SOT seems to be associated with dental caries experience; however, this information was not available.

Dental screening, treatment, and rehabilitation should be part of the pre-operative care protocol for patients in the transplant waiting list [11,25,30]. Patients under transplantation therapy usually are systemically compromised, present underlying conditions, and use several medicines. It is possible that general dentists feel insecure to provide dental care to this population [32]. To our knowledge, there are few specialized transplantation oral health care centers in Brazil. In this context, it is important to identify oral health demands of this population to nurture policymakers' decisions. In this matter, this study provided some insight into the oral health status from both, kidney and liver patients under transplantation therapy attending an oral health care program in a populous state in Brazil.

\section{Conclusion}

Dental caries experience was high in kidney and liver, pre-Tx and post-Tx, patients. This highlights the demand for treatment need in this population.

\section{Authors' Contributions}

\begin{tabular}{|c|c|c|}
\hline AJSC & (D) https://orcid.org/0000-0003-1905-4124 & Conceptualization, Investigation, Formal Analysis, and Writing - Original Draft Preparation. \\
\hline LSC & https://orcid.org/0000-0001-9648-6815 & Formal Analysis and Writing - Original Draft Preparation. \\
\hline LCSC & https://orcid.org/0000-0002-7080-7710 & Formal Analysis and Writing - Original Draft Preparation. \\
\hline MESS & https://orcid.org/0000-0001-5803-7568 & Formal Analysis and Writing - Original Draft Preparation. \\
\hline MHNGA & (iD) https://orcid.org/0000-0001-8794-5725 & Conceptualization, Methodology, Formal Analysis, and Writing - Review and Editing. \\
\hline
\end{tabular}

\section{Financial Support}

None.

\section{Conflict of Interest}

The authors declare no conflicts of interest.

\section{Data Availability}


The data used to support the findings of this study can be made available upon request to the corresponding author.

\section{References}

[1] Barker CF, Markmann JF. Historical overview of transplantation. Cold Spring Harb Perspect Med 2013; 3(4):a014977. https://doi.org/10.1101/cshperspect.a014977

[2] Farkas S, Hackl C, Schlitt HJ. Overview of the indications and contraindications for liver transplantation. Cold Spring Harb Perspect Med 2014; 4(5): a015602. https://doi.org/10.1101/cshperspect.a015602

[3] Augustine J. Kidney transplant: New opportunities and challenges. Cleve Clin J Med 2018; 85(2):138-44. https://doi.org/10.3949/ccjm.85gr.18001

[4] National Kidney Foundation. K/DOQI clinical practice guidelines for chronic kidney disease: evaluation, classification, and stratification. Am J Kidney Dis 2002; 39(2 Suppl 1): S1-266.

[5] Zheng L, Chen X, Luo T, Ran X, Hu J, Cheng Q, et al. Early-onset type 2 diabetes as a risk factor for end-stage renal disease in patients with diabetic kidney disease. Prev Chronic Dis 2020; 17:200076. https://doi.org/10.5888/pcd 17.200076

[6] Benderli Y, Erdilek D, Koray F, Telci A, Turan N. The relation between salivary IgA and caries in renal transplant patients. Oral Surg Oral Med Oral Pathol Oral Radiol Endod 2000; 89(5):588-93. https://doi.org/10.1067/moe.2000.105144

[7] Nylund KM, Meurman JH, Heikkinen AM, Furuholm JO, Ortiz F, Ruokonen HM. Oral health in patients with renal disease: a longitudinal study from predialysis to kidney transplantation. Clin Oral Investig 2018; 22(1):339-47. https://doi.org/10.1007/s00784-017-2118-y

[8] Shetty P, Hegde MN, Eraly SM. Evaluation of salivary parameters and dental status in adult hemodialysis patients in an Indian population. J Clin Exp Dent. 2018; 10(5):e419-e24. https://doi.org/10.4317/jced.54633

[9] Ahmadieh A, Baharvand M, Fallah F, Djaladat H, Eslani M. Oral microflora in patients on hemodialysis and kidney transplant recipients. Iran J Kidney Dis 2010; 4(3):227-31.

[10] Menezes CR, Pereira AL, Ribeiro CC, Chaves CO, Guerra RN, Thomaz ÉB, et al. Is there association between chronic kidney disease and dental caries? A case-controlled study. Med Oral Patol Oral Cir Bucal 2019; 24(2):e21 1-e6. https://doi.org/10.4317/medoral.22737

[11] Schmalz G, Kauffels A, Kollmar O, Slotta JE, Vasko R, Müller GA, et al. Oral behavior, dental, periodontal and microbiological findings in patients undergoing hemodialysis and after kidney transplantation. BMC Oral Health 2016; 16(1):72. https://doi.org/10.1186/s12903-016-0274-O

[12] Ziebolz D, Hraský V, Goralczyk A, Hornecker E, Obed A, Mausberg RF. Dental care and oral health in solid organ transplant recipients: a single center cross-sectional study and survey of German transplant centers. Transpl Int 2011; 24(12):1179-88. https://doi.org/10.1111/j.1432-2277.2011.01325.x

[13] Machiulskiene V, Campus G, Carvalho JC, Dige I, Ekstrand KR, Jablonski-Momeni A, et al. Terminology of Dental Caries and Dental Caries Management: Consensus Report of a Workshop Organized by ORCA and Cariology Research Group of IADR. Caries Res 2019; 54(1):7-14. https://doi.org/10.1159/000503309

[14] Costa SM, Adelário AK, Vasconcelos M, Abreu MHNG. Explanatory models for dental caries: from the organismic to ecosystemic model. Pesq Bras Odontoped Clin Integr 2012; 12(2):285-91. https://doi.org/10.4034/PBOCI.2012.122.20

[15] Bertossi D, Barone A, Iurlaro A, Marconcini S, De Santis D, Finotti M, et al. Odontogenic orofacial infections. J Craniofac Surg 2017; 28(1):197-202. https://doi.org/10.1097/SCS.0000000000003250

[16] Rustemeyer J, Bremerich A. Necessity of surgical dental foci treatment prior to organ transplantation and heart valve replacement. Clin Oral Investig 2007; 11(2):171-4. https://doi.org/10.1007/s00784-007-0101-8

[17] Guggenheimer J, Eghtesad B, Close JM, Shay C, Fung JJ. Dental health status of liver transplant candidates. Liver Transpl 2007; 13(2):280-6. https://doi.org/10.1002/1t.21038

[18] Holt CD. Overview of immunosuppressive therapy in solid organ transplantation. Anesthesiol Clin 2017; 35(3):36580. https://doi.org/10.1016/j.anclin.2017.04.001

[19] Helenius-Hietala J, Aberg F, Meurman JH, Isoniemi H. Increased infection risk postliver transplant without pretransplant dental treatment. Oral Dis 2013; 19(3):271-8. https://doi.org/10.1111/j.1601-0825.2012.01974.x

[20] Guggenheimer J, Mayher D, Eghtesad B. A survey of dental care protocols among US organ transplant centers. Clin Transplant 2005; 19(1):15-8. https://doi.org/10.1111/j.1399-0012.2005.00251.x

[21] Palmer SC, Ruospo M, Wong G, Craig JC, Petruzzi M, De Benedittis M, et al. Dental Health and Mortality in People With End-Stage Kidney Disease Treated With Hemodialysis: A Multinational Cohort Study. Am J Kidney Dis 2015; 66(4):666-76. https://doi.org/10.1053/j.ajkd.2015.04.051

[22] Nascimento SV, Gonzalez AM, Aguiar Roza B, Pimentel CFMG, Schirmer J, Mucci S, et al. Development of routine dental care for liver transplant outpatients. Transplant Proc 2018; 50(3):779-83. https://doi.org/10.1016/j.transproceed.2018.02.054

[23] Brasil. Ministério da Saúde. DATASUS. Informações de Saúde- TABNET [homepage]. Brasília: Ministério da Saúde; 2010. Available from: https://www2.datasus.gov.br/DATASUS/index.php?area=02 [Accessed on August 15, 2020]. [In Portuguese]. 
[24] Schmalz G, Wendorff H, Berisha L, Meisel A, Widmer F, Marcinkowski A, et al. Association between the time after transplantation and different immunosuppressive medications with dental and periodontal treatment need in patients after solid organ transplantation. Transpl Infect Dis 2018; 20(2):e12832. https://doi.org/10.1111/tid.12832

[25] Kauffels A, Schmalz G, Kollmar O, Slotta JE, Weig M, Groß U, et al. Oral findings and dental behaviour before and after liver transplantation - a single-centre cross-sectional study. Int Dent J 2017; 67(4):244-51. https://doi.org/10.1111/idj.12290

[26] Didilescu AC, Lazu A, Pronk C, Vacaru RP, Brand HS. Clinical periodontal and dental findings in liver transplant patients: a systematic review and meta-analysis. Br Dent J 2020; 228(2):108-16. https://doi.org/10.1038/s41415020-1196-4

[27] Instituto Brasileiro de Geografia e Estatística - IBGE. Cidades [homepage]. Rio de Janeiro: IBGE; 2017. Available from: https://cidades.ibge.gov.br/brasil/mg/panorama. [Accessed on August 15, 2020]. [In Portuguese].

[28] Minas Gerais. MG Transplantes. Fundação Hospitalar do Estado de Minas Gerais. Epidemiologia e Estatística de Notificação, Captação e Transplantes de Órgãos e Tecidos em Minas Gerais. Belo Horizonte: MG Transplantes; 2016. Available from: https://www.fhemig.mg.gov.br/atendimento/sistema-estadual-de-transplantes/mgtransplantes/numeros-de-transplantes. [Accessed on August 15, 2020]. [In Portuguese].

[29] World Health Organization (WHO). Oral Health Surveys: Basic Methods. Geneva: WHO; 2013. Available from: https://apps.who.int/iris/bitstream/handle/10665/97035/9789241548649_eng.pdf? sequence=1. [Accessed on August 15, 2020].

[30] Ramaglia AHF, Salzedas-Netto AA, Monteiro MM, Pimentel-Mota CFMG, Abranches DC, Rangel EB, et al. Need for dental treatment in patients on the waiting list for liver and simultaneous pancreas-kidney transplant at a single center. Rev Col Bras Cir 2019; 46(4):e20192224. https://doi.org/10.1590/0100-6991e-20192224

[31] Oliveira CS, Galdino TM, Limeira FIR, Moreira AN, de Magalhães CS, Abreu LG. Is dental caries associated with liver transplantation? A systematic review and meta-analysis. Oral Dis 2020. https://doi.org/10.1111/odi.13439 [Epub ahead of print].

[32] Lins L, Bittencourt PL, Evangelista MA, Lins R, Codes L, Cavalcanti AR, et al. Oral health profile of cirrhotic patients awaiting liver transplantation in the Brazilian Northeast. Transplant Proc 2011; 43(4):1319-21. https://doi.org/10.1016/j.transproceed.2011.03.063

[33] Peres MA, Macpherson LMD, Weyant RJ, Daly B, Venturelli R, Mathur MR, et al. Oral diseases: a global public health challenge. Lancet 2019; 394(10194):249-60. https://doi.org/10.1016/So140-6736(19)31146-8

[34] Costa SM, Martins CC, Pinto MQC, Vasconcelos M, Abreu MHNG. Socioeconomic factors and caries in people between 19 and 60 years of age: an update of a systematic review and meta-analysis of observational studies. Int $\mathrm{J}$ Environ Res Public Health 2018; 15(8):1775. https://doi.org/10.3390/ijerph15081775

[35] Brasil. Ministério da Saúde. SB Brasil 2010. Pesquisa Nacional de Saúde Bucal: resultados principais. Ministério da Saúde: Brasília: 2012. Available from: https://bvsms.saude.gov.br/bvs/publicacoes/pesquisa_nacional_saude_bucal.pdf. [Accessed on August 15, 2020]. [In Portuguese]. 